\title{
Colombo declaration on epidemiology in South East Asia
}

DOI: https://doi.org/10.4038/jccpsl.v25i4.8235

COLOMBO Declaration on Epidemiology in South East Asia has been released with the consensus reached after the deliberations of the $1^{\text {st }}$ South East Asia Regional Group Meeting of International Epidemiological Association and $24^{\text {th }}$ Annual Scientific Sessions of the College of Community Physicians of Sri Lanka in Colombo, Sri Lanka on 19-21 September 2019.

The Regional Public Health/Epidemiology Associations who worked on this and deliberated to make it final are: the College of Community Physicians of Sri Lanka, Epidemiology Association of Bangladesh, Epidemiology Foundation of India, Indian Association of Preventive and Social Medicine, Indian Public Health Association, Indian Society for Medical Statistics, Indonesian Public Health Association, Korean Epidemiology Society and Nepal Public Health Association. 


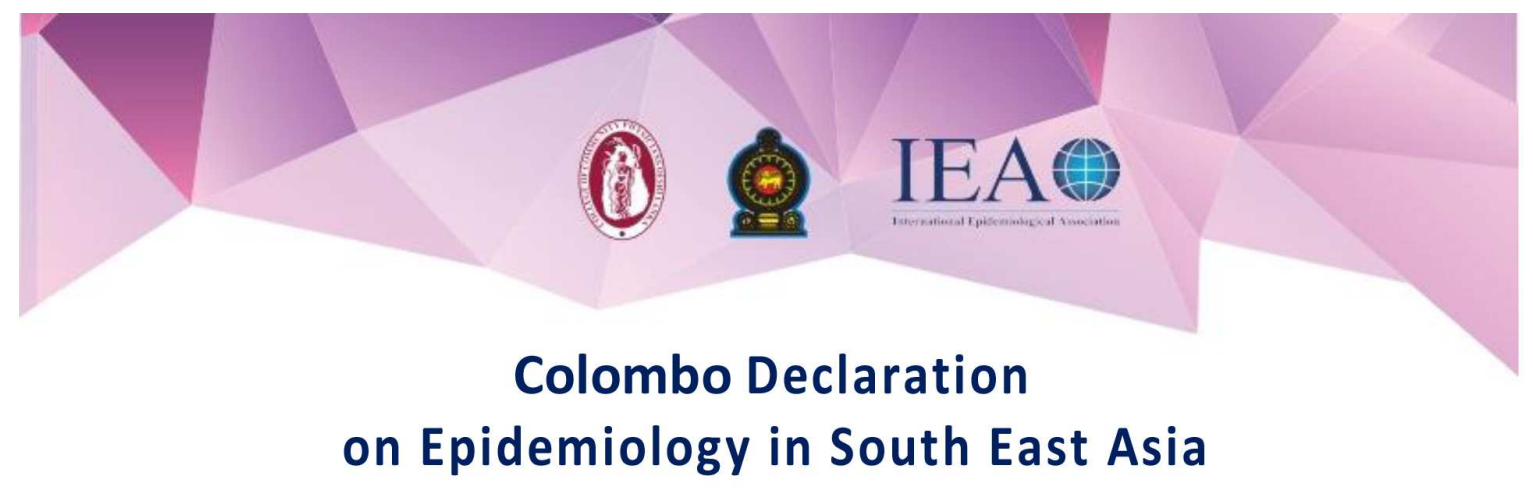

Over the years, epidemiology has made huge contributions to the understanding of the disease and improvement of human health. This has been possible only because of the use of powerful and sophisticated epidemiological tools. Epidemiologic research has generated a wide variety of data that have led to the practice of evidence-based medicine. The countries of South East Asia Region lag behind markedly when it comes to epidemiologic research and publications, primarily due to the resource crunch be it funding, infra-structure or trained manpower. The key to improve the health status of countries of the region and attainment of the Sustainable Development Goals, lies in the development and improved practices of epidemiology.

The Colombo Declaration on Epidemiology in South East Asia is based on the deliberations by the delegates of the Conference and representatives of the Regional Public Health/ Epidemiology Associations held during $1^{\text {st }}$ South East Asia Regional Group Meeting of the International Epidemiological Association and 24th Annual Scientific Sessions of the College of Community Physicians of Sri Lanka in Colombo, Sri Lanka on 19-21 September 2019. Having noted the current status of epidemiological training and research in the countries of South East Asia Region, and their impact on human health, we, the participants of the Meeting endorse the following strategies for capacity building in epidemiology, boosting epidemiological research and fruitful utilization of its outcomes towards attainment of Sustainable Development Goals in the years to come:

a) Institutionalize epidemiology as key to enhancement of human health. Principles of epidemiology including operational research should be utilized for finding solutions to complex health issues and improving outcomes of health programmes.

b) Promote collaborative research to achieve solid conclusions. Focus of research be shifted to a combination of clinical and population approaches. Collaborative research between the clinical collaborators and the epidemiologists can expand the funding base and provide richer evidence for decision making.

c) Strengthen and reform epidemiological training for improving human resources and maintain a database of trained manpower. Institutions of excellence should adopt the leadership role and support other institutions in capacity building through joint training and faculty exchange programmes.

d) Implement policies for career progression of personnel trained in epidemiology at district, state and national levels. Provide them environment and resources for carrying out research so as to improve their expertise and make policies for making them responsible for finding solutions to health-related problems.

e) Identify the urgent need to accelerate epidemiological research to overcome the challenges posed to human health due to changing environment; changing lifestyle; and emerging and re-emerging infectious diseases.

We urge all member countries of South East Asia Region, various Public Health/ Epidemiological Associations and networks, NGOs, public and private sectors, media and other organizations of the civil society to advocate, collaborate and promote all aspects of the Colombo Declaration on Epidemiology in South East Asia.

\section{Regional Group Coordinators}

\section{Dr Vinod Srivastava}

Secretary

Epidemiology Foundation of India
Dr Janaki Vidanapathirana

President

College of the Community Physicians of Sri Lanka 